\title{
Homocystinuria due to Cystathionine Synthase Deficiency
}

\author{
STUDIES OF NITROGEN BALANCE AND \\ SULFUR EXCRETION
}

\author{
Jeffery R. Poole, S. Harvey Mudd, E. Brinson Conerly, and \\ William A. Edwards
}

From the Digestive and Hereditary Diseases Branch, National Institute of

Arthritis, Metabolism and Digestive Diseases, and the Laboratory of

General and Comparative Biochemistry, National Institute of Mental

Health, Bethesda, Maryland 20014

\begin{abstract}
A в S T R A C T Apparent nitrogen balances and urinary sulfur excretions were determined for normal subjects, seven cystathionine synthase-deficient patients, and a single cystathioninuric patient on semisynthetic diets containing low-adequate amounts of methionine and very low amounts (12 mg daily, or less) of cystine. The amounts of supplemental cystine required to prevent abnormally high nitrogen or sulfur losses were determined. The five cystathionine synthase-deficient patients who had low residual activities of this enzyme detected in fibroblast and/or liver extracts did not lose more nitrogen or sulfur on diets virtually devoid of cystine than did the normal subjects. These results suggest that the widely expressed opinion that cystine is an essential amino acid for cystathionine synthase-deficient patients requires modification. Residual enzyme activity of only a few percent of normal may obviate such a cystine requirement. These results are compatible with, and lend support to, the working hypothesis which states that the pyridoxine response in cystathionine synthase-deficient patients is mediated by an increase in the residual activity of the affected enzyme.
\end{abstract}

\section{INTRODUCTION}

The transsulfuration pathway in mammals provides a route whereby the sulfur of methionine becomes the sulfur of cyst(e)ine. Methionine is demethylated via two intermediates to form homocysteine, which is combined with serine by the action of cystathionine synthase (EC 4.2.1.22) to yield the thioether, cystathionine $\left(\mathrm{HOOC}\left(\mathrm{N} \mathrm{H}_{2}\right) \mathrm{CH} \mathrm{CH} \mathrm{CH}_{2} \mathrm{~S} \mathrm{CH}_{2} \mathrm{CH}\left(\mathrm{NH}_{2}\right) \mathrm{COOH}\right)$

Received for publication 17 April 1974 and in revised form 27 December 1974. (reaction 1). Cystathionine is cleaved by $\boldsymbol{\gamma}$-cystathionase (EC 4.4.1.1) to form cysteine and $\alpha$-ketobutyrate (reaction 2):

$$
\begin{aligned}
& \text { homocysteine }+ \text { serine } \underset{\text { synthase }}{\stackrel{\text { cystathionine }}{\longrightarrow}} \\
& \text { cystathionine }+\mathrm{H}_{2} \mathrm{O}
\end{aligned}
$$

$$
\begin{aligned}
& \text { cystathionine }+\mathrm{H}_{2} \mathrm{O} \stackrel{\gamma \text {-cystathionase }}{\longrightarrow} \\
& \text { cysteine }+\alpha \text {-ketobutyrate }+\mathrm{NH}_{3}
\end{aligned}
$$

homocysteine + serine $\rightarrow$ cysteine

$$
+\alpha \text {-ketobutyrate }+\mathrm{NH}_{3}
$$

Humans have been discovered with genetically determined deficient activity of either cystathionine synthase $(1,2)$ or $\gamma$-cystathionase (3-5), the hallmark excretory abnormalities of which are, respectively, homocystinuria and cystathioninuria.

Early in the study of homocystinuria, it was pointed out that a block in the transsulfuration pathway would be expected to decrease the ability to synthesize cysteine $(1,6)$. Normal humans do not require exogenous cyst(e)ine $(7,8)$. In contrast, it seemed possible that patients with sufficiently severe cystathionine synthase deficiency would require an exogenous supply of this amino acid. For these patients, cyst(e)ine would have become an essential amino acid $(1,6)$. This theoretical expectation was apparently confirmed when Brenton, Cusworth, Dent, and Jones carried out nitrogen balance studies on a single homocystinuric patient. This patient went into negative nitrogen balance when daily cystine intake was decreased to $85 \mathrm{mg}$. Nitrogen balance was restored when the cystine intake was increased to $1,085 \mathrm{mg}$ (9). In subsequent reviews and texts it has

The Journal of Clinical Investigation Volume 55 May 1975.1033-1048 
TABLE I

Patients

\begin{tabular}{|c|c|c|c|c|c|}
\hline Patient & Sex & Age & $\begin{array}{c}\text { Admission } \\
\text { weight }\end{array}$ & Demonstration of enzyme deficiency & $\begin{array}{l}\text { Responsive to } \\
\text { pyridoxine }\end{array}$ \\
\hline & & $y r$ & $k g$ & & \\
\hline \multicolumn{6}{|c|}{ Cystathionine synthase deficient } \\
\hline Wi. Cr. & $\mathrm{M}$ & 15 & 79.3 & Fibroblast assay (patient 16 , reference 18 ) & Yes* \\
\hline $\mathrm{Bu} . \mathrm{Ha}$. & M & 8 & 29.3 & Fibroblast assay (patient 32, reference 18 ) & Noł \\
\hline Jo. Ho. & $\mathrm{F}$ & 31 & 69.5 & Liver, fibroblast assays (patient 31 , references 18,19 ) & Yes (19) \\
\hline Ja. Is. & $\mathrm{F}$ & 13 & 62.4 & Fibroblast assay (patient 1 , reference 18 ) & Yes§ \\
\hline Ro. Kr. & $\mathrm{F}$ & 20 & 63.9 & Fibroblast assay (patient 6 , reference 18 ) & Yes§ \\
\hline Th. Kr. & M & 31 & 79.5 & Fibroblast assay (patient 8 , reference 18 ) & Yes (19) \\
\hline Ol. Ma. & $\mathrm{F}$ & 19 & 55.9 & Fibroblast assay (patient 34 , reference 18 ) & No\| \\
\hline Ca. Me. & $\mathrm{F}$ & 20 & 64.5 & Fibroblast assay $\uparrow$ & Yes§ \\
\hline Fr. Mi. & $\mathbf{M}$ & 12 & 54.5 & Fibroblast assay $\uparrow$ & No** \\
\hline Ba. Re. & $\mathrm{F}$ & 31 & 67.6 & Fibroblast assay (patient 35, reference 18 ) & Noई \\
\hline Vi. Sw. & $\mathrm{F}$ & 17 & 62.0 & Fibroblast assay $\mathbb{\|}$ & Noł‡ \\
\hline \multicolumn{6}{|c|}{ Cystathioninuric } \\
\hline Ge. Po. & M & 21 & 74.9 & Indirect evidence only§§ & Yes \|\| \\
\hline
\end{tabular}

* Personal communication from Dr. A. Sass-Kortasak. Patient previously reported (20).

$\ddagger$ Personal communication from Dr. N. Holtzmann.

$\S$ Personal communication from Dr. V. McKusick.

|| Patient's urinary and plasma homocystine and methionine values remained essentially unchanged despite the administration of $500 \mathrm{mg}$ pyridoxine $\cdot \mathrm{HCl}$ daily for 11 days. Serum folate was normal.

I Previously unpublished specific activities of cystathionine synthase, assayed in fibroblast extracts without addition of pyridoxal phosphate, or in the presence of pyridoxal phosphate added at final concentrations of $0.1,1.0$, and $5.0 \mathrm{mM}$ were as follows: Ca. Me., 0.46, 0.64, 0.83, 0.73; Fr. Mi., 0.59, 0.70, 0.96, 0.65 (mean of two assays); Vi. Sw. 0, 0, 0, 0 (i.e., <0.10). Activities are in nmol cystathionine $/ \mathrm{mg}$ protein $/ 135 \mathrm{~min}$; control mean, 31.7 ; range, 3.7-60.0 (18).

** Personal communication from Dr. G. Morrow, III. Morrow's observation was confirmed during the present studies. Hypermethioninemia, homocystinemia, hypocystinemia, and homocystinuria all remained relatively constant during 10 days of treatment with a daily oral dose of $500 \mathrm{mg}$ pyridoxine $\cdot \mathrm{HCl}$.

¥ After taking $3 \mathrm{mg}$ folic acid and $300 \mathrm{mg}$ pyridoxine $\cdot \mathrm{HCl}$ daily for several months, the patient had elevated urinary homocystine and methionine levels. 1 mo after decreasing the folic acid to $2 \mathrm{mg}$ twice weekly and discontinuing the pyridoxine, no significant change in urinary homocystine or methionine was noted.

$\$ \&$ Cystathionine was elevated in plasma and urine. Patient was free of nongenetic conditions known to cause cystathioninuria (21).

||| The classification of Ge. Po. as a responder to $B_{6}$ is based upon the response of his cystathioninuric brother (21).

been widely and generally stated that cystine is an essential amino acid for cystathionine synthase-deficient patients $(2,10-17)$.

Recent indications of genetic heterogeneity in cystathionine synthase-deficient patients (18), in conjunction with an increasing realization of the possible functional significance of small residual activities of cystathionine synthase in deficient patients (19), led us to question whether the generally accepted opinion of the essential nature of cyst(e)ine for such patients were not an oversimplification. As explained more fully in the Discussion, it seemed possible that patients with as little as $1-2 \%$ of the normal activity of cystathionine synthase might not require cyst(e)ine. To test this hypothesis, we determined the amount of cystine required to maintain short-term nitrogen balance in a series of cystathionine synthase-deficient patients. As will be reported, we found that under the conditions employed those cystathionine synthase-deficient patients with low, but detectable, residual enzyme activities had no greater need for exogenous cystine than did normal volunteer subjects.

\section{METHODS}

Subjects. The control subjects were normal volunteers aged 18-24 yr, in good health as indicated by medical histories, physical examinations, and laboratory tests, including urinary amino acid analyses.

Patients. Information regarding the patients is summarized in Table $\mathrm{I}$. Presently, certain vitamin $\mathrm{B}_{6}$-responsive cystathionine synthase-deficient patients are maintained, as a therapeutic measure, on large supplemental doses of pyridoxine $(16,17,22)$. To study such patients in "basal" states, their vitamin $B_{6}$ intakes were limited to that contained in their diets for a minimum of 1 mo before the beginning of the present studies. This was sufficient time 
for the urinary homocystine excretions of responsive patients previously under treatment with pyridoxine to return to pretreatment levels (19) and for urinary 4-pyridoxic acid excretions to return to normal (see Results). The cystathioninuric patient had not recently received pyridoxine treatment.

Experimental plan. During the present work, several studies were performed, each requiring a different diet. (a) When nitrogen balance and sulfur excretion studies were performed concomitantly, each subject received a constant natural diet (the "equilibration diet") until nitrogen balance was attained (approximately 6-15 days), after which he was placed on a semisynthetic diet (the "experimental diet") containing approximately the same amount of nitrogen as the equilibration diet. For a period of 0-3 days after switching to the experimental diet, adjustments were made in caloric intake and the other dietary components until the subject's weight remained stable and the diet was acceptable to him. Thereafter, the experimental diet became constant, and was divided into 6-day dietary periods, during each of which a specified amount of L-cystine was added to the diet. During all studies the subjects were inpatients at the Clinical Center of the National Institutes of Health. They were instructed to maintain reasonably constant levels of activity, avoiding strenuous exercise. 24-h urine collections were made under toluene and were refrigerated until volumes were measured and samples frozen. Stool collections were pooled for each 72-h period. Fasting blood specimens were obtained during the latter half of each dietary period. (b) For sulfur partition studies, subjects received constant natural diets calculated to provide half of the dietary sulfur in the form of methionine and half in the form of cystine. These diets provided approximately 0.14 $\mathrm{mmol}$ of methionine and $0.07 \mathrm{mmol}$ of cystine (i.e., 0.14 mg-atom of cystine sulfur) $/ \mathrm{kg}$ body wt.

Diets. All of the diets were prepared and served under the supervision of a dietician trained in the techniques of metabolic balance studies. The equilibration diets provided between 10.0 and $11.2 \mathrm{~g}$ of nitrogen (as indicated by calculation and analyses), 1,175-1,563 $\mathrm{mg}$ of methionine, and $912-1,197 \mathrm{mg}$ of cystine. These dietary amino acid intakes were calculated from published tables (23).

The semisynthetic experimental diet consisted of foods and beverages low in methionine and cystine, including cookies, muffins, and pancakes prepared from Cellu Low Protein Baking Mix, Cellu Pasta Imitation Macaroni (both Cellu products from Chicago Dietetic Supply House, Inc., La Grange, Ill.), butter oil, jelly, air mints, sour balls, vinegar, oil, various vegetables, fruits, and fruit juices, carbonated beverages, coffee, tea, and sugar. Controlyte (The Doyle Pharmaceutical Company, Minneapolis, Minn.), a high calorie dietary supplement with trace protein content $(1.4 \mathrm{mg}$ methionine and $0.7 \mathrm{mg}$ cystine $/ 100 \mathrm{~g}$ ) was used in the form of a fruit-flavored beverage as a source of calories and as a vehicle for the supplemental amino acids. Together, these materials provided $0.4-1.2 \mathrm{~g}$ of nitrogen (calculation and analysis), approximately $14-55 \mathrm{mg}$ of methionine (calculation), and 3-12 $\mathrm{mg}$ of cystine (calculation). To these materials were added supplemental amino acids as shown below and in the individual studies.

Amino acids. The eight essential amino acids plus arginine, histidine, and tyrosine were added to the experimental diet in their pure L-forms in the approximate quantities found in $20 \mathrm{~g}$ of whole egg protein. The amounts added were (in grams per day): L-arginine, 1.31 (as equivalent quantity of hydrochloride salt); L-histidine, 0.48 ; L-isoleucine, 1.33 ; L-leucine, 1.76 ; L-lysine, 1.28 (as equivalent quan- tity of hydrochloride salt) ; L-methionine, 0.63 ; L-phenylalanine, 1.16 ; L-threonine, 1.00 ; L-tryptophan, 0.33 ; L-tyrosine, 0.86 ; L-valine, 1.49. For patient Fr. Mi. an additional 300 $\mathrm{mg}$ of L-lysine and $170 \mathrm{mg}$ of L-methionine were added to meet the published amino acid requirements for his age group (24). Otherwise, methionine and cystine were added as specified in the individual studies. Glycine was added to bring the total supplemental amino acid nitrogen to $10.0 \mathrm{~g}$. Thus, total nitrogen content of the experimental diet (food nitrogen plus supplemental amino acid nitrogen) ranged from 10.4 to $11.2 \mathrm{~g} /$ day, depending on each subject's weight and caloric requirements.

$V$ itamin and mineral supplements. While on the experimental diet all subjects received one $0.5-\mathrm{mg}$ pyridoxine $\cdot \mathrm{HCl}$ capsule daily and one especially formulated combination vitamin and mineral capsule which supplied $10,000 \mathrm{U}$ vitamin A, $400 \mathrm{U}$ vitamin $\mathrm{D}, 5 \mathrm{mg}$ thiamine mononitrate, 5 $\mathrm{mg}$ riboflavin, $25 \mathrm{mg}$ niacinamide, $2 \mu \mathrm{g}$ cyanocobalamin, 5 $\mathrm{mg}$ calcium pantothenate, $100 \mathrm{mg}$ ascorbic acid, $10 \mathrm{mg}$ ferrous sulfate, $1 \mathrm{mg}$ copper sulfate, $150 \mu \mathrm{g}$ calcium iodate, 1 mg manganese sulfate, $5 \mathrm{mg}$ magnesium oxide, and $1.5 \mathrm{mg}$ zinc sulfate. During initial studies, five subjects (Wi. Cr., Ba. Ha., Ba. Re., Ka. Ro., and An. To.) did not receive these two capsules, but instead one commercial multivitamin tablet (Dayalets-M, Abbott Laboratories, North Chicago, Ill.) daily. The contents of this tablet differed from those of the especially formulated combination vitamin and mineral capsule only in that the commercial tablet provided a total of $2.0 \mathrm{mg}$ of pyridoxine $\cdot \mathrm{HCl}$ and approximately twice the amount of each of the minerals. Throughout all of the studies, each subject received $2 \mathrm{mg}$ of folic acid twice weekly.

Medications. Patients Jo. Ho., Ca. Me., and Ba. Re. each necessarily received certain medication(s) during the present studies. Patient Jo. Ho. received $60 \mathrm{mg}$ isoxsuprine $\cdot \mathrm{HCl}$ daily throughout all of the studies. Patient $\mathrm{Ca}$. Me. received $30 \mathrm{mg}$ phenobarbital twice daily and $100 \mathrm{mg}$ diphenylhydantoin twice daily throughout the studies. Patient Ba. Re. received $75 \mathrm{mg}$ of amitriptyline $\cdot \mathrm{HCl}$ and $50 \mathrm{mg}$ hydrochlorthiazide daily throughout her first two studies. Urinary sulfur partition (Table VI) was measured during the first study, and nitrogen balances on 109, 309, and $509 \mathrm{mg}$ cystine (Table IV) were determined during the second. During her second study she was also given $300 \mathrm{mg}$ and subsequently $400 \mathrm{mg}$ of sulfinpyrazone daily. During her third study (nitrogen balance on 8 and $1,008 \mathrm{mg}$ cystine [Table IV]) she was no longer on any of the above medications, and she received $50 \mathrm{mg}$ spironolactone and $400 \mathrm{mg}$ of dipyridamole daily.

Methionine loads. For methionine loading studies, the patient was placed on the constant natural diet used for sulfur partition studies. After the total sulfur output had remained relatively constant for several days, L-methionine was given in gelatin capsules, each containing $0.25 \mathrm{~g}$ of $\mathrm{L}-$ methionine. The subject was fasted from 10 p.m. the previous night, and the amino acid was administered at 8 a.m. in a dose of $0.5 \mathrm{mmol} / \mathrm{kg}$ body wt. Breakfast was fed at 9 a.m. 24-h urines were collected before and after the methionine load.

Analytical methods. Nitrogen analyses were performed by use of a micro-Kjeldahl method (25). Values obtained for fecal nitrogen excretions over $72 \mathrm{~h}$ were divided by 3 to give mean daily fecal nitrogen outputs. Urinary creatinines were determined by the method of Chasson, Grady, and Stanley (26). Urinary and plasma amino acids were determined with an automatic amino acid analyzer with the buffer system of Spackman, Stein, and Moore (27). 4Pyridoxic acid concentrations in the urine were determined 
by the microprocedure of Woodring, Fisher, and Storvick (28). Serum folate concentrations were determined by the procedure of Harper (29).

Differential analyses of urinary inorganic sulfate, total sulfate (i.e., inorganic sulfate + "ethereal" sulfate), and total sulfur were performed according to the general procedure of Rosenheim and Drummond, as specified in Hawk, Oser, and Summerson (30). A detailed description is given, since the methods we are currently using involve a number of modifications of the original method.

For phosphate removal, up to $12.5 \mathrm{ml}$ of urine was diluted with water to a volume of approximately $25 \mathrm{ml}$ in a $50-\mathrm{ml}$ volumetric flask, and the solution made basic with $\mathrm{NH}_{4} \mathrm{OH}$ (approximately $5 \mathrm{~N}$ ) with phenolphthalein as indicator. After addition of $5 \mathrm{ml} 5 \% \quad \mathrm{NH}_{4} \mathrm{Cl}$ and an aqueous slurry containing $0.75 \mathrm{~g} \mathrm{MgCO}_{3}$ (Baker reagent: $4 \mathrm{MgCO}_{3} \cdot \mathrm{Mg}$ $(\mathrm{OH})_{2} \cdot n_{2} \mathrm{O}$ ) in $5 \mathrm{ml}$, the preparation was diluted to volume and inverted five times. The mixture was inverted at 3-min intervals for $15 \mathrm{~min}$, allowed to stand for $15 \mathrm{~min}$, mixed again, and centrifuged. Aliquots of the supernatant fluid were taken for analyses.

For analysis of inorganic sulfate, an aliquot (usually 5 $\mathrm{ml}$ ) of the phosphate-free supernatant fluid was brought to a total volume of $10 \mathrm{ml}$ in a $50-\mathrm{ml}$ beaker and acidified with $\mathrm{HCl}$ to bromphenol blue. To precipitate sulfate ions, the sample was chilled for $15 \mathrm{~min}$ at $4^{\circ} \mathrm{C}$, and mixed with $2 \mathrm{~m}$ cold benzidine reagent $(5 \mathrm{~g}$ benzidine dihydrochloride and $50 \mathrm{ml} 1 \mathrm{~N} \mathrm{HCl}$ in a total volume of $250 \mathrm{ml}$, made fresh each week). After $5 \mathrm{~min}$ at $4^{\circ} \mathrm{C}, 5 \mathrm{ml} 95 \%$ acetone was added, and the mixture allowed to stand an additional $15 \mathrm{~min}$ at $4^{\circ} \mathrm{C}$. Precipitate was isolated by filtration through glass fiber filter paper in Gooch crucibles and washed twice with $2-\mathrm{ml}$ portions of cold $95 \%$ acetone and once with a 5-ml portion. The precipitate, together with the filter paper, was transferred to a $250 \mathrm{ml}$ Erlenmeyer flask. Boiling water was used to wash the crucible to ensure complete transfer and to suspend the filter paper and precipitate. The precipitate dissolved slowly during the subsequent titration. Titration was carried out with $0.01 \mathrm{~N} \mathrm{NaOH}$ at approximately $100^{\circ} \mathrm{C}$ with constant mechanical stirring to a lasting phenol-red end point. The normality of the $\mathrm{NaOH}$ was determined at each use by titration against commercial standard $\mathrm{HCl}$.

For analysis of total sulfate (inorganic and ethereal), an aliquot $(5-10 \mathrm{ml})$ of the phosphate-free supernatant fluid was subjected to acid hydrolysis to convert ethereal sulfate to inorganic sulfate. The aliquot was mixed with $1 \mathrm{ml} 1 \mathrm{~N}$ $\mathrm{HCl}$ in a porcelain evaporating dish and taken to dryness over boiling water. (Unless otherwise specified, heating and drying were routinely done on a boiling water bath.) The residue was transferred to a $50-\mathrm{ml}$ beaker with two $5-\mathrm{ml}$ portions of distilled water. No acidification of this sample was required before the subsequent steps, which were the same as those described above for the acidified aliquot analyzed for inorganic sulfate.

For analysis of total sulfur, an aliquot $(5-10 \mathrm{ml})$ of the phosphate-free supernatant fluid was subjected to oxidation to ensure that all sulfur would be in the form of inorganic sulfate. The aliquot was taken to dryness in an evaporating dish together with $0.25 \mathrm{ml}$ Benedict's reagent $(20 \% \mathrm{Cu}$ $\left.\left[\mathrm{NO}_{3}\right]_{2} \cdot 3 \mathrm{H}_{2} \mathrm{O}, 5 \% \mathrm{KClO}_{3}\right)$, reconstituted with $1 \mathrm{ml}$ distilled $\mathrm{H}_{2} \mathrm{O}$ and $0.25 \mathrm{ml}$ Benedict's reagent, and again taken to dryness. The residue was heated to redness with a Bunsen burner for $3 \mathrm{~min}$. The carbon-free residue was reconstituted with $1 \mathrm{ml} 2 \mathrm{~N} \mathrm{HCl}$ and taken to dryness. One drop of $2 \mathrm{~N} \mathrm{HCl}$ was added to the evaporating dish, and the dry residue was transferred with two $5-\mathrm{ml}$ portions of distilled $\mathrm{H}_{2} \mathrm{O}$ to a $50-\mathrm{ml}$ beaker. A clear blue solution should result from this procedure. Subsequent steps were the same as those used for the $10-\mathrm{ml}$ acidified aliquot analyzed for inorganic sulfate except that the precipitate was washed once with $2 \mathrm{ml}$ cold $50 \%$ acetone and then with 2 $\mathrm{ml}$ and $5 \mathrm{ml}$ cold $95 \%$ acetone.

Further modifications were required for samples very low in sulfur because of low dietary intake. Initial samples of approximately $1 \%$ of a daily urinary volume were diluted to $21 \mathrm{ml}$. $10 \mathrm{ml}$ of the diluted specimen was treated for phosphate removal with half the reagent quantities previously described and ending with a volume of $25 \mathrm{ml}$. Appropriate aliquots, usually $7.5 \mathrm{ml}$, were then treated as usual except that precipitates were titrated with $0.005 \mathrm{~N} \mathrm{NaOH}$.

Precipitates containing less than $5 \mu \mathrm{mol}$ or more than 25 $\mu \mathrm{mol}$ sulfate often gave unsatisfactory results, and sample sizes were adjusted accordingly. It was also found that total sulfur results tended to be spuriously low if the starting sample exceeded $1-2 \%$ of the total daily urine volume. Nonsulfate sulfur was calculated as total sulfur minus total sulfate. Since this value and that for ethereal sulfate (total sulfate minus inorganic sulfate) usually depend upon relatively small differences between two larger experimentally determined quantities, it was important to perform the three determinations (inorganic sulfate, total sulfate, total sulfur) for a given specimen in parallel during a single analytical run. All determinations were done in duplicate, and the mean result is reported. Usually four urine samples could be handled in this way during a single day. Determinations were repeated if disagreement between duplicates was more than $10 \%$.

Fecal specimens were assayed for total sulfur only by a modification of the above method. After collection, samples were homogenized with approximately 2 weights $\mathrm{H}_{2} \mathrm{O}$ and stored frozen. Aliquots of $3 \mathrm{~g}$ total weight were mixed with further $\mathrm{H}_{2} \mathrm{O}$ to a total volume of $10 \mathrm{ml}$. $0.5 \mathrm{ml}$ Benedict's reagent was added, and the suspension was dried in an evaporating dish over boiling $\mathrm{H}_{2} \mathrm{O}$ and heated for $3 \mathrm{~h}$ in a muffle oven, attaining a temperature of $300^{\circ} \mathrm{C}$ within an hour and a final temperature of $650-700^{\circ} \mathrm{C}$. After cooling, the residue was dissolved in $1 \mathrm{ml} 2 \mathrm{~N} \mathrm{HCl}$ and dried. The cooled residue was reconstituted with 1 drop $2 \mathrm{~N} \mathrm{HCl}$ and two $5-\mathrm{ml}$ portions of $\mathrm{H}_{2} \mathrm{O}$ and transferred to a $25-\mathrm{ml}$ volumetric flask. Phosphate removal, as previously described, was carried out by using the appearance of the intense blue color of the copper-ammonia complex ion as indicator, corresponding to $\mathrm{a} \mathrm{pH}$ of $7.0-7.5$. $10 \mathrm{ml}$ of the phosphate-free supernatant fluid was then assayed according to the usual procedure for inorganic sulfate. In 13 runs using this procedure the mean recovery of an added mixture containing equal amounts of methionine sulfur and cyst(e)ine sulfur was $56.8 \pm 3.3 \%$ (SE) (range, $34-74 \%$ ).

Growth of fibroblasts and sensitive assay of cystathionine synthase activity. These procedures were performed essentially as previously described (18).

Treatment of the data. In calculating nitrogen balances, only those days were considered during which the patients were on the experimental diets and adjustments of caloric intakes had been completed. From these, all days in which urine collections were lost or known to be incomplete were eliminated, leading to the omission of five of a potential total of 204 subject-days for the studies reported here. The urinary creatinine excretions for the remaining days for each patient were then analyzed by the methods of Grubbs to identify any statistical outliers (31). Excretions for these outlying days (a total of 11) were considered suspect and were eliminated from the subsequent analyses. Nitrogen bal- 
ances were then obtained by subtracting the daily values for urinary and fecal nitrogen from the total nitrogen intake provided by food, vitamin and mineral capsules, supplemental amino acids, and medications.

Excess urinary sulfur was calculated as dietary sulfur intake minus urinary sulfur excretion. The shift from the equilibration diets to the experimental diets involved decreases in total sulfur intakes (unlike nitrogen intakes, which remained relatively constant). Thus, sulfur excretions usually decreased during the first 2 days on the experimental diets and assumed more or less constant values from the 3rd day through the end of the period. For this reason, only those days eligible after the statistical analyses described above and included among the last 3 days on the experimental diets were used in calculating excess urinary sulfur values.

\section{RESULTS}

The homocystine excretion of cystathionine synthasedeficient patients is known to be affected by two vitamins, pyridoxine $(16,17,19)$ and folic acid $(32,33)$. Some patients respond to large doses of $\mathrm{B}_{6}$ with decreases in plasma and urinary homocystine and methionine, whereas other, unrelated patients show no such response $(16,17,19)$. These responses to $B_{6}$ are thought to be genetically determined manifestations of heterogeneity in cystathionine synthase-deficient patients (18). Therefore, each patient was classified with respect to his pyridoxine responsiveness (Table I), and the experiments were designed so that each patient would be in his basal state during the present studies, rather than in pyridoxine-induced response. To determine relative pyridoxine intakes, urinary 4-pyridoxic acid excretions were measured. The excretion of this compound provides an index of $\mathrm{B}_{\boldsymbol{s}}$ intake, being equivalent to approximately $50 \%$ of the vitamin ingested by subjects on normal diets or receiving small supplements (34). For the present studies, 4-pyridoxic acid excretions were measured during the latter half of both the equilibration and experimental diet periods (Table II). During the equilibration periods no vitamin supplements were given, and 4-pyridoxic acid excretions were close to or within the ranges reported for humans on normal diets by other workers using the same method of determination (0.27-1.08 mg/day [34]; 0.65-1.32 mg/day [28]). During the experimental dietary periods the first five subjects to be studied (Wi. Cr., Ba. Ha., Ba. Re., Ka. Ro., and An. To.) received $2 \mathrm{mg}$ pyridoxine daily in commercial multivitamin tablets and had slightly higher urinary excretions of 4-pyridoxic acid than during the preceding equilibration periods when no vitamin supplement was given. Under no circumstances, however, did urinary 4-pyridoxic acid excretion exceed $1.65 \mathrm{mg}$, a value only slightly above the normal range. In subsequent studies the pyridoxine $\cdot \mathrm{HCl}$ supplement was decreased from the $2.0 \mathrm{mg}$ supplied by the commercial multivitamin tablets to $0.5 \mathrm{mg}$. On this regimen all subjects had lower urinary 4-pyridoxic acid excretions
TABLE II

Urinary 4-Pyridoxic Acid Excretions

\begin{tabular}{|c|c|c|c|}
\hline \multirow[b]{2}{*}{ Subject } & \multicolumn{2}{|c|}{ 4-Pyridoxic acid excretion } & \multirow{2}{*}{$\begin{array}{c}\text { Pyridoxine } \cdot \mathrm{HC} \\
\text { supplement on } \\
\text { experimental } \\
\text { diet* }\end{array}$} \\
\hline & $\begin{array}{c}\text { Equilibration } \\
\text { diet }\end{array}$ & $\begin{array}{c}\text { Experimental } \\
\text { diet }\end{array}$ & \\
\hline & \multicolumn{2}{|c|}{$m g / d a y$} & $m g / d a y$ \\
\hline \multicolumn{4}{|c|}{ Normal volunteers } \\
\hline Ba. Ha. & 0.75 & 1.13 & 2.0 \\
\hline Ka. Ro. & 0.80 & 1.25 & 2.0 \\
\hline An. To. & 0.55 & 0.83 & 2.0 \\
\hline Re. Da. & 0.75 & 0.68 & 0.5 \\
\hline An. Na. & 1.15 & 0.50 & 0.5 \\
\hline St. Po. & 0.50 & 0.50 & 0.5 \\
\hline \multicolumn{4}{|c|}{ Cystathionine synthase deficient } \\
\hline Vi. Sw. & 1.10 & 0.40 & 0.5 \\
\hline Ba. Re. & 1.03 & 0.50 & 0.5 \\
\hline Fr. Mi. & 0.58 & 0.30 & 0.5 \\
\hline Wi. Cr. & $1.37 \ddagger$ & $1.65 \ddagger$ & 2.0 \\
\hline Jo. Ho. & $0.95 \ddagger$ & $0.57 \ddagger$ & 0.5 \\
\hline Ro. Kr. & 0.98 & 0.40 & 0.5 \\
\hline Ca. Me. & 0.88 & 0.35 & 0.5 \\
\hline \multicolumn{4}{|c|}{ Cystathioninuric (presumptive $\gamma$-cystathionase deficient) } \\
\hline Ge. Po. & 1.20 & 0.35 & 0.5 \\
\hline
\end{tabular}

* Supplied as either $2.0 \mathrm{mg}$ in Dayalets-M tablet or as $0.5 \mathrm{mg}$ in separate capsule.

$\ddagger$ Value represents average of two measurements.

during the experimental periods than during the preceding equilibration periods.

Cystathionine synthase-deficient subjects tend to develop abnormally low serum folate concentrations when receiving normal folate intakes (32). To ensure that all subjects were replete with folate during the present experiments, each was routinely given supplemental folic acid ( $2 \mathrm{mg}$ twice weekly). Several patients had subnormal serum folic acid concentrations upon admission to hospital (lowest, $3 \mathrm{ng} / \mathrm{ml}$; normal, 5-21 $\mathrm{ng} / \mathrm{ml}$ ), but repeat determinations before, or during, the experimental diet periods were in all cases within or above the normal limits.

Nitrogen balance, excess urinary sulfur, and sulfur balance

Normal controls. A typical balance study for a normal subject is shown in Fig. 1. At the outset of this experiment the subject was changed from an equilibration diet to an isonitrogenous experimental diet on which the total methionine intake was $685 \mathrm{mg}$ and the total cystine intake $10 \mathrm{mg}$. After the first 2 days, because of an apparent weight gain, the calorie intake was reduced from 49.0 to $45.1 \mathrm{cal} / \mathrm{kg}$, and the weight was effectively stabilized. On day 9 the methionine intake was increased to $1,155 \mathrm{mg}$ by the addition of further supplemental free amino acid. The urine collections for days 9 and 14 were known to be incomplete. The creatinine excretion for day 7 indicated this collection 
TABLE III

Apparent Nitrogen Balance and Excess Urinary Sulfur: Normal Volunteers on Cystine-Poor Diet*

\begin{tabular}{|c|c|c|c|c|c|}
\hline \multirow[b]{2}{*}{ Subject $\ddagger$} & \multicolumn{2}{|c|}{ Sulfur amino acid intake } & \multirow{2}{*}{$\begin{array}{l}\text { Apparent nitrogen } \\
\text { balance }\end{array}$} & \multicolumn{2}{|c|}{ Excess urinary } \\
\hline & Met & Cys & & Nitrogen & Sulfur \\
\hline & \multicolumn{2}{|c|}{$m g / d a y$} & $g / d a y( \pm S E)$ & $g / d a y( \pm S E)$ & $m g-a t o m / d a y( \pm S E)$ \\
\hline \multicolumn{6}{|l|}{ Females } \\
\hline Ba. Ha. & 662 & 9 & $+0.31 \pm 0.30$ & $+1.32 \pm 0.24$ & $-0.3 \pm 0.1$ \\
\hline St. Po.§ & 661 & 3 & $+0.01 \pm 0.22$ & $+0.72 \pm 0.22$ & $-1.7 \pm 0.2$ \\
\hline Ka. Ro. & 670 & 11 & $-0.15 \pm 0.27$ & $+0.54 \pm 0.22$ & $-1.6 \pm 0.6$ \\
\hline An. To. & 659 & 10 & $+1.32 \pm 0.49$ & $+1.64 \pm 0.49$ & $-1.1 \pm 1.3$ \\
\hline \multicolumn{6}{|l|}{ Males } \\
\hline Re. Da. & 683 & 11 & $+0.22 \pm 0.38$ & $+1.43 \pm 0.42$ & $-1.6 \pm 0.4$ \\
\hline \multirow{2}{*}{ Fr. Li. } & 667 & 8 & $-0.53 \pm 0.13$ & $+0.36 \pm 0.13$ & $-2.1 \pm 0.1$ \\
\hline & 1,137 & 8 & $+0.39 \pm 0.36$ & $+1.03 \pm 0.40$ & $+0.1 \pm 0.2$ \\
\hline An. Na. & 670 & 9 & $+2.30 \pm 0.45$ & $+2.71 \pm 0.44$ & $-0.1 \pm 0.5$ \\
\hline \multirow[t]{2}{*}{ Jo. Ro. } & 685 & 10 & $+0.34 \pm 0.45$ & $+1.16 \pm 0.40$ & $-2.6 \pm 0.4$ \\
\hline & 1,155 & 10 & $-0.43 \pm 0.24$ & $+0.24 \pm 0.22$ & $-1.8 \pm 0.5$ \\
\hline
\end{tabular}

* Experimental plan, diet, and methods of treating the data are described in Methods. The actual data from which these balances were calculated have been deposited with the National Auxiliary Publications Service (NAPS document no. 02536; ASIS/NAPS, Microfiche Publications, New York). The nitrogen intakes ranged from 10.49-11.07 g/day. Caloric intakes varied from 39.0-54.8 cal $/ \mathrm{kg}$ body wt and for each subject had been adjusted before the experimental period and were then kept constant, so that during these periods weight changes were small. $\mathrm{Ba}$. Ha. was exceptional in that the initial caloric intake was excessive and was decreased on day 3 of the study. During the study this subject gained $1.4 \mathrm{~kg}$. $\ddagger$ All subjects were normal volunteers between 18 and 24 yr old.

$\S$ The equilibration diet for this subject was unusual and provided approximately $450 \mathrm{mg}$ of methionine and $375 \mathrm{mg}$ of cystine, with additional nitrogen furnished by supplemental L-glycine, bringing the total dietary nitrogen to approximately $10.9 \mathrm{~g}$.

to be an outlier (31). These days were eliminated from consideration. It is seen that on these virtually cystinefree dietary regimens this normal control had mean nitrogen excretions which deviated from absolute balance by less than $5 \%$ of the total intake of $11.0 \mathrm{~g}$ of nitrogen. That is, the balances fell within what has been defined by other workers as the "zone of nitrogen equilibrium" $(35,36)$.

The total daily sulfur intake on the equilibration diet for this experiment was $19.4 \mathrm{mg}$-atom sulfur, and the daily urinary excretion was $18.7 \pm 0.6$ (not shown in Fig. 1). The intake was decreased to $4.67 \mathrm{mg}$-atom sulfur on the experimental diet, whereupon the urinary sulfur excretion decreased for 2 days, then remained relatively constant. The excess urinary sulfur for this experimental period was calculated using the values for days 6 and 8, day 7 being eliminated as a possible outlier. For these days the mean urinary sulfur excretion was $7.25 \mathrm{mg}$-atom/day. Excess urinary sulfur thus was equal to $4.67-7.25=-2.6 \mathrm{mg}$-atom/day. Note that when urinary sulfur exceeds sulfur intake, the excess urinary sulfur has been assigned a negative value, indicative of the fact that total bodily sulfur has decreased by at least this amount. The increase in the methionine supplement on day 9 raised the total intake to $7.82 \mathrm{mg}$ - atom. The excess urinary sulfur decreased somewhat to $-1.8 \pm 0.5 \mathrm{mg}$-atom for the last 3 days of this period included in the analysis.

In Table III is presented a summary of all similar experiments on normal volunteers. Each of the four male and four female subjects was either within the zone of equilibrium or in positive nitrogen balance on dietary regimens containing 659-685 $\mathrm{mg}$ methionine and 3-11 $\mathrm{mg}$ cystine. Urinary nitrogen excretions generally reflect the metabolic system and are not complicated by the difficulties inherent in obtaining accurate estimates of fecal nitrogen output during short-term metabolic balance periods. Therefore, data on the "excess urinary nitrogen," (calculated as total dietary nitrogen - urinary nitrogen) are also compiled in Table III. These subjects excreted from 0.36 to $2.71 \mathrm{~g}$ less nitrogen in their daily urine than their daily intakes on diets containing 659-685 mg methionine and 3-11 mg cystine. On the same regimens, the urinary sulfur losses of most subjects slightly exceeded their dietary intakes, the maximum loss being $-2.6 \mathrm{mg}$-atom sulfur/day. Increasing the methionine intake decreased (Jo. Ro.) or entirely ablated (Fr. Li.) the excess urinary sulfur loss.

To gain a preliminary indication of the relationship between excess urinary sulfur and the sulfur balance 
and how these parameters are affected by limitation of amino acids other than methionine and cystine, a further experiment was carried out with two normal control subjects (De. Wa. and Ma. Sw.). After equilibration periods, these subjects were given experimental diets analogous to the experimental diets used for the studies reported in Table III, except that the methionine intakes were increased to $1,209-1,219 \mathrm{mg}$ in an effort to avoid excessive urinary sulfur losses. On this diet one subject (De. Wa.) was in nitrogen equilibrium $(+0.30 \pm 0.13 \mathrm{~g} /$ day $)$, whereas, unexpectedly, the second subject (Ma. Sw.) was below the zone of equilibrium but by less than $1 \mathrm{SEM}(-0.65 \pm 0.11 \mathrm{~g} /$ day $)$. Under these conditions, the excess urinary sulfurs were +0.8 and $+0.1 \pm 0.6 \mathrm{mg}$-atom/day. Fecal sulfurs were also measured, and sulfur balances were calculated as total dietary sulfur - (urinary sulfur + fecal sulfur). Sulfur losses in the stools were small relative to urinary losses, ${ }^{1}$ and the resulting sulfur balances were +0.1 and $-1.6 \pm$ $0.5 \mathrm{mg}$-atom/day.

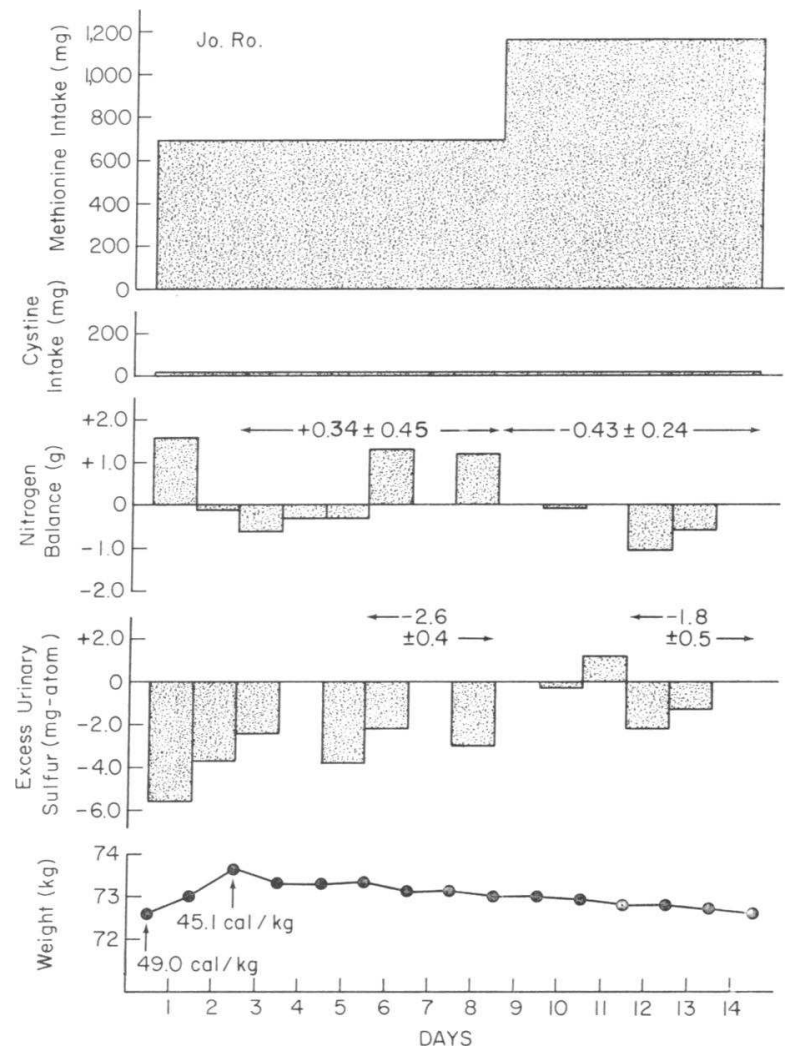

FIGURE 1 A representative study of a normal volunteer subject (Jo. Ro.). Daily methionine intakes were 685 and $1,155 \mathrm{mg}$. Daily intakes of cystine and nitrogen were 10 $\mathrm{mg}$ and $11.0 \mathrm{~g}$, respectively, throughout. The figures for apparent nitrogen balance and excess urinary sulfur excretions are indicated as mean $\pm 1 \mathrm{SE}$ in $\mathrm{g}$ nitrogen/day and mg-atom sulfur/day, respectively. See text for further explanation.

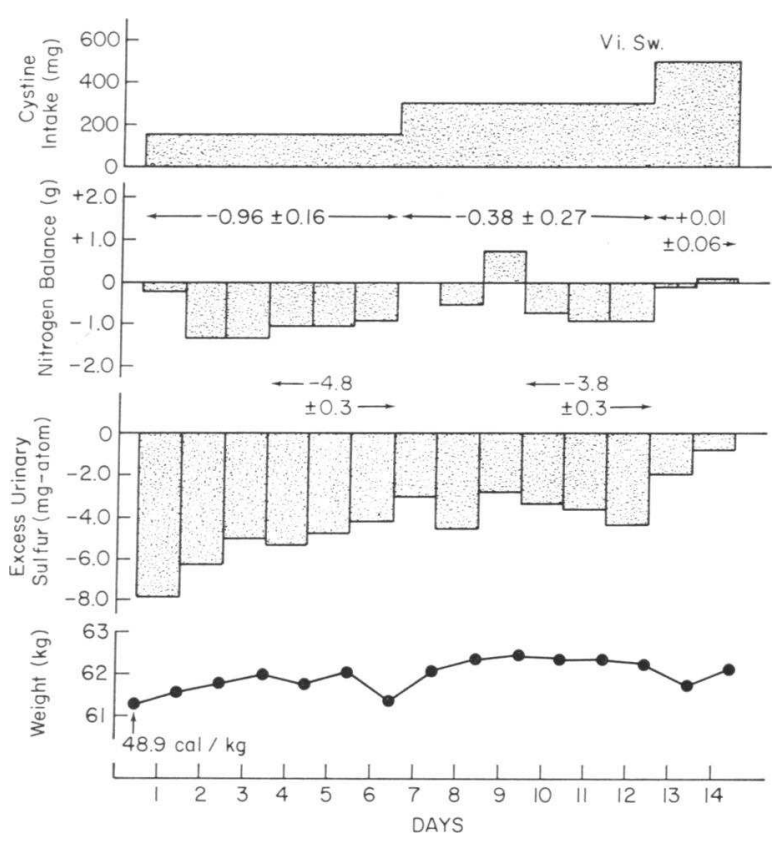

Figure 2 A study of a cystathionine synthase-deficient, $\mathrm{B}_{\mathrm{c}}$-nonresponsive patient ( $\mathrm{Vi}$. Sw.) on daily cystine intakes of 155,305 , and $505 \mathrm{mg}$. Daily intakes of methionine and nitrogen were $655 \mathrm{mg}$ and $10.36 \mathrm{~g}$, respectively, throughout. Only 2 days of study could be completed on the intake of $505 \mathrm{mg}$ of cystine. See text and Fig. 1 for further explanation.

After 6 days on the experimental diet, the phenylalanine supplement was decreased so that the subjects were receiving only $100 \mathrm{mg}$ daily of phenylalanine, a marginal amount for maintenance of nitrogen equilibrium on the tyrosine intake of these subjects (37). As expected, on this diet both subjects were near the lower end of the zone of nitrogen equilibrium $(-0.51 \pm 0.13$ and $-0.63 \pm 0.24 \mathrm{~g} / \mathrm{day})$. On the same regimen, sulfur losses increased so that the excess urinary sulfur values were $-1.5 \pm 0.3$ and $-2.5 \pm 0.1 \mathrm{mg}$-atom/day, and the sulfur balances were $-2.0 \pm 0.3$ and $-4.6 \pm 0.5 \mathrm{mg}$-atom/ day.

Cystathionine synthase-deficient patients. A study of a cystathionine synthase-deficient, $B_{6}$-nonresponsive patient (Vi. Sw.) is shown in Fig. 2. This study was similar in design to those carried out with the control subjects, except that each of the experimental dietary regimens contained some supplemental cystine. The total daily intake of this amino acid was increased progressively during the three periods from 155 to 305 ,

${ }^{1}$ This finding was typical. The fecal sulfur content of 21 stool samples from normal control subjects and cystathionine synthase-deficient patients on equilibration or sulfur partition diets averaged $13.2 \pm 1.3 \%$ of the total urinary sulfur (range $3.4-30.0 \%$ ). The samples from the patients did not differ significantly from those for normal controls. 


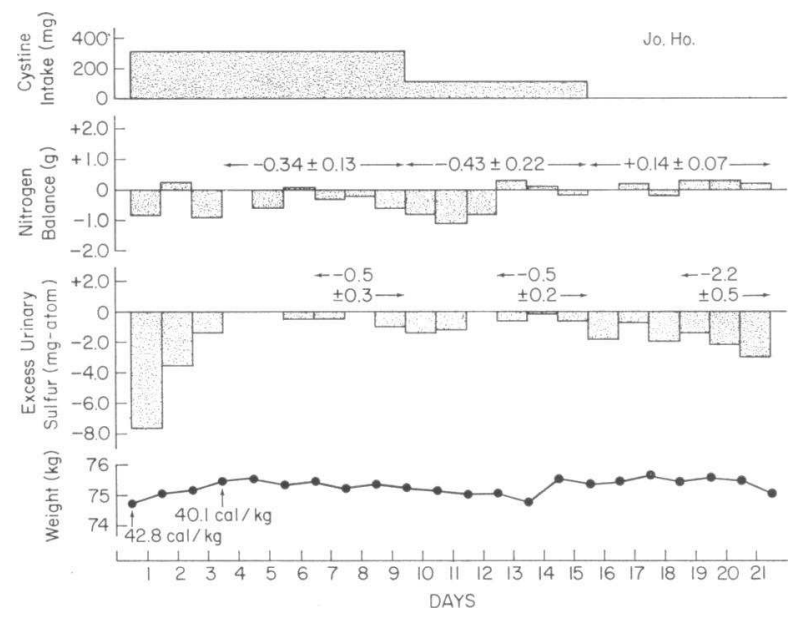

Figure 3 A study of a cystathionine synthase-deficient, $B_{6}-$ responsive patient (Jo. Ho.) on daily cystine intakes of 312 , 112 , and $12 \mathrm{mg}$. Daily intakes of methionine and nitrogen were $677 \mathrm{mg}$ and $10.64 \mathrm{~g}$, respectively, throughout. The urinary creatinine excretion for day 4 indicated this collection to be a statistical outlier. See text and Fig. 1 for further explanation.

then to $505 \mathrm{mg}$. On the lowest cystine intake the nitrogen balance of this patient was $-0.96 \pm 0.15 \mathrm{~g} /$ day, a value significantly below the zone of equilibrium. The value for excess urinary nitrogen was less positive than the value for any control subject (Table III). The excess urinary sulfur for this period was $-4.8 \pm 0.3$ $\mathrm{mg}$-atom/day, a much more negative value than was observed for any control subject, even on lower cystine intakes (Table III). When the cystine intake was increased to $305 \mathrm{mg}$, the nitrogen balance for patient Vi. Sw. was in the lower region of the zone of equilibrium. The excess urinary nitrogen remained somewhat low. The excess urinary sulfur decreased to $-3.8 \pm 0.3 \mathrm{mg}$ atom/day, a value still outside the range observed in control subjects. The increase in cystine intake to 505 $\mathrm{mg}$ apparently decreased the excessive losses of nitrogen and sulfur, although only 2 days could be completed on this dietary regimen. Thus, as expected on the basis of the results of Brenton et al. (9), this cystathionine synthase-deficient, $\mathrm{B}_{\boldsymbol{\theta}}$-nonresponsive patient failed to remain in balance unless supplied with a substantial amount of dietary cystine.

The results obtained in two studies of a second nonresponsive subject, Ba. Re. were less clear-cut. In the initial balance study (Table IV, study II) this patient was below the zone of nitrogen equilibrium and lost excessive urinary nitrogen and sulfur on the lowest cystine intake $(109 \mathrm{mg}) .^{2}$ The urinary losses were re-

\footnotetext{
${ }^{2}$ After these dietary studies had been completed, we became aware of the not uncommon practice in the formulation of medications of adding calcium sulfate as an excipient.
}

duced to acceptable levels by increased cystine intake, but the nitrogen balance remained equivocally below the zone of equilibrium. During a second balance study (Table IV, study III), similar observations were recorded with respect to urinary sulfur loss, but the nitrogen balances remained low and the urinary nitrogen losses appeared to be inconsistent with the results of study II. During these studies the two periods of lowest cystine intakes had to be discontinued during the 5th and 4th days, respectively, because of nausea, irritability, lassitude, and one episode of vomiting. These symptoms have been noted in subjects deprived of essential amino acids (7). Ba. Re. tolerated well the diets containing more cystine. Thus, the clinical results, as well as most of the chemical measurements, suggest that this patient has a cyst(e)ine requirement, but the present studies do not conclusively demonstrate this requirement because of the failure of high cystine intakes to bring all parameters unequivocally within the control ranges. The clinical status of $\mathrm{Ba}$. Re. was such that she required multiple medications during these studies, and it is possible that one or more of these medications may have affected the results obtained.

For the additional five cysthathionine synthase-deficient patients studied (Table IV, and Fig. 3 ) the results were quite different. For none of these patients was the nitrogen balance significantly below the zone of nitrogen equilibrium, even on diets as low in exogenous cystine content as could be experimentally attained. The urinary nitrogen losses for four of the five were within the control range.

A parallel conclusion may be drawn from the results on sulfur excretion. On the lowest cystine intakes, the excess urinary sulfur excretions of these five patients ranged from +1.1 to $-2.3 \mathrm{mg}$-atom/day. Thus, under these conditions the excess urinary sulfurs of these patients were less than those of Vi. Sw. or Ba. Re. but similar to the excess urinary sulfurs of most control subjects on similar dietary regimens. Measurements of fecal sulfur were performed during the studies of Ro. Kr. and $\mathrm{Ca}$. Me. The calculated sulfur balances were -4.9 \pm 0.2 and $-3.4 \pm 0.1 \mathrm{mg}$-atom sulfur/day, respectively.

$\gamma$-Cystathionase-deficient patient. Included in Table IV are the results of a study of Ge. Po., a patient with a presumptive block at another step in the transsulfuration pathway, the $\gamma$-cystathionase reaction (21). On a diet virtually free of cystine this cystathioninuric, $\mathrm{B}_{\mathrm{o}-\mathrm{re}}$

Being regarded as "inert," this ingredient is not specified in descriptions of the medications. Therefore, all medications taken by any patient during the course of this work were analyzed for inorganic sulfate and total sulfur. The major resulting uncertainty occurred in the case of $\mathrm{Ba}$. Re., who received as much as $1.5 \mathrm{mg}$-atom inorganic sulfate and 0.2 $\mathrm{mg}$-atom organic sulfur in her medications. It is difficult to correct for these intakes because the portions absorbed are not known (see footnote $\|$ of Table IV). 
TABLE IV

Apparent Nitrogen Balance and Excess Urinary Sulfur: Cystathionine Synthase-Deficient or Cystathioninuric Patients on Cystine-Poor Diet with Varying Supplements*

\begin{tabular}{|c|c|c|c|c|c|}
\hline \multirow[b]{2}{*}{ Subjects $\ddagger$} & \multicolumn{2}{|c|}{ Sulfur amino acid intake } & \multirow{2}{*}{$\begin{array}{l}\text { Apparent nitrogen } \\
\text { balance }\end{array}$} & \multicolumn{2}{|c|}{ Excess urinary } \\
\hline & Met & Cys & & Nitrogen & Sulfur \\
\hline \multicolumn{4}{|c|}{ Cystathionine synthase deficient } & & \\
\hline Vi. Sw. & $\begin{array}{l}655 \\
655 \\
655\end{array}$ & $\begin{array}{l}155 \\
305 \\
505\end{array}$ & $\begin{array}{l}-0.96 \pm 0.16 \\
-0.37 \pm 0.27 \\
+0.01 \pm 0.06 \S\end{array}$ & $\begin{array}{r}0.00 \pm 0.17 \\
+0.04 \pm 0.30 \\
+0.52 \pm 0.06\end{array}$ & $\begin{array}{r}-4.8 \pm 0.3 \\
-3.8 \pm 0.3 \\
-\end{array}$ \\
\hline (study III) & $\begin{array}{l}667 \\
667 \\
667 \\
662 \\
662\end{array}$ & $\begin{array}{r}109 \\
309 \\
509 \\
8 \\
1,008\end{array}$ & $\begin{array}{l}-0.88 \pm 0.77 \| \\
-0.22 \pm 0.51 \\
-0.67 \pm 0.30 \\
-0.68 \pm 0.49 \| \\
-0.95 \pm 0.30\end{array}$ & $\begin{array}{l}+0.02 \pm 0.64 \\
+0.56 \pm 0.50 \\
+0.45 \pm 0.86 \\
+0.58 \pm 0.49 \\
-0.10 \pm 0.34\end{array}$ & $\begin{array}{l}-5.9 \text { to }-7.6 \| \Phi \\
-3.8 \text { to }-4.0 \pm 0.8 \rrbracket \\
-0.1 \text { to }-0.3 \pm 1.5 \Phi \\
-5.7 \text { to }-7.3 \| \Phi \\
+1.1 \text { to }-0.4 \pm 1.0 \Phi\end{array}$ \\
\hline Fr. Mi. & $\begin{array}{l}822^{* *} \\
822 \\
822\end{array}$ & $\begin{array}{r}5 \\
80 \\
155\end{array}$ & $\begin{array}{l}+1.07 \pm 0.14 \\
+2.16 \pm 0.33 \\
+0.99 \pm 0.41\end{array}$ & $\begin{array}{l}+1.79 \pm 0.15 \\
+2.76 \pm 0.35 \\
+1.82 \pm 0.43\end{array}$ & $\begin{array}{l}+1.1 \pm 0.2 \\
+1.9 \pm 0.3 \\
-0.6 \pm 0.6\end{array}$ \\
\hline Wi. Cr. & $\begin{array}{l}682 \\
682\end{array}$ & $\begin{array}{r}7 \\
107\end{array}$ & $\begin{array}{l}+0.58 \pm 0.21 \\
+2.21 \pm 0.29\end{array}$ & $\begin{array}{l}+1.48 \pm 0.19 \\
+3.13 \pm 0.29\end{array}$ & $\begin{array}{l}-2.3 \pm 0.3 \\
-1.2 \pm 0.3 \ddagger \ddagger\end{array}$ \\
\hline Jo. Ho. & $\begin{array}{l}677 \\
677 \\
677\end{array}$ & $\begin{array}{r}12 \\
112 \\
312\end{array}$ & $\begin{array}{l}+0.13 \pm 0.07 \\
-0.43 \pm 0.22 \\
-0.34 \pm 0.13\end{array}$ & $\begin{array}{l}+0.75 \pm 0.05 \\
+0.34 \pm 0.22 \\
+0.39 \pm 0.19\end{array}$ & $\begin{array}{l}-2.2 \pm 0.5 \\
-0.5 \pm 0.2 \\
-0.5 \pm 0.3\end{array}$ \\
\hline Ro. Kr. & 659 & 3 & $-0.60 \pm 0.14$ & $+0.14 \pm 0.13$ & $-2.3 \pm 0.2$ \\
\hline Ca. Me. & 644 & 4 & $+0.87 \pm 0.19$ & $+1.49 \pm 0.14$ & $-1.3 \pm 0.1\|\|$ \\
\hline \multicolumn{6}{|c|}{ Cystathioninuric (presumptive $\gamma$-cystathionase deficient) } \\
\hline Ge. Po. & 673 & 6 & $-0.11 \pm 0.37$ & $+0.71 \pm 0.38$ & $-3.8 \pm 0.0$ \\
\hline
\end{tabular}

* See Table II and Methods. The actual data from which these balances were calculated have been deposited with the National Auxiliary Publication Service (NAPS document no. 02536). Nitrogen intakes ranged from 10.36 to $11.20 \mathrm{~g} /$ day. Caloric intakes varied from 36.5 to 59.5 calories $/ \mathrm{kg}$ body wt and were adjusted as described in Table III. The initial intake for Wi. Cr. was excessive and during the period on $107 \mathrm{mg}$ cystine this subject gained $1.9 \mathrm{~kg}$. $\ddagger$ See Table I for further details on these subjects.

$\S$ Based on 2 days only, after which study was discontinued because of a death in the patient's family.

|| The studies of $\mathrm{Ba}$. Re. on $8 \mathrm{mg}$ and $109 \mathrm{mg}$ cystine had to be discontinued during days 4 and 5 , respectively, because of nausea, vomiting, and weakness. The excess urinary sulfur values are those for the last complete days of these studies.

T This patient was receiving some sulfur in her medications. The values for excess urinary sulfur were calculated on the alternative assumptions that $(a)$ all of this sulfur was absorbed (yielding the less negative values for each study) or $(b)$ none of this sulfur was absorbed (more negative values).

** An additional $170 \mathrm{mg}$ of L-methionine was added to the diet to meet the requirement for this $15 \mathrm{yr}$-old boy (24). ¥ This study was the initial patient study, and the experimental protocol differed slightly from the standard one adopted subsequently and described in Methods. This patient was gaining significant weight for the first 4 days on the experimental diet. His weight was stabilized after caloric adjustments on days 5 and 7 . The excessive caloric intake may have accounted for the relatively high nitrogen retention during the dietary period he was receiving $107 \mathrm{mg}$ cystine.

\|\| For this patient, in contrast to others studied, the daily urinary sulfur excretion did not reach a constant value until the 5th day on the experimental diet. Therefore, the mean excess urinary sulfur excretions averaged over the last 4,3 , and 2 days decreased progressively, being equal to $-3.6 \pm 1.5,-2.2 \pm 0.9$, and $-1.3 \pm 0.1 \mathrm{mg}$-atom sulfur, respectively. The last value is regarded as the most valid, and has been entered in the table.

sponsive patient remained within the zone of nitrogen equilibrium with a balance of $-0.11 \pm 0.37 \mathrm{~g} /$ day (Fig. 4). His urinary nitrogen loss was acceptable. His ex- cess urinary sulfur was $-3.8 \mathrm{mg}$-atom/day, slightly more negative than the values observed for normal control subjects (Table III). 


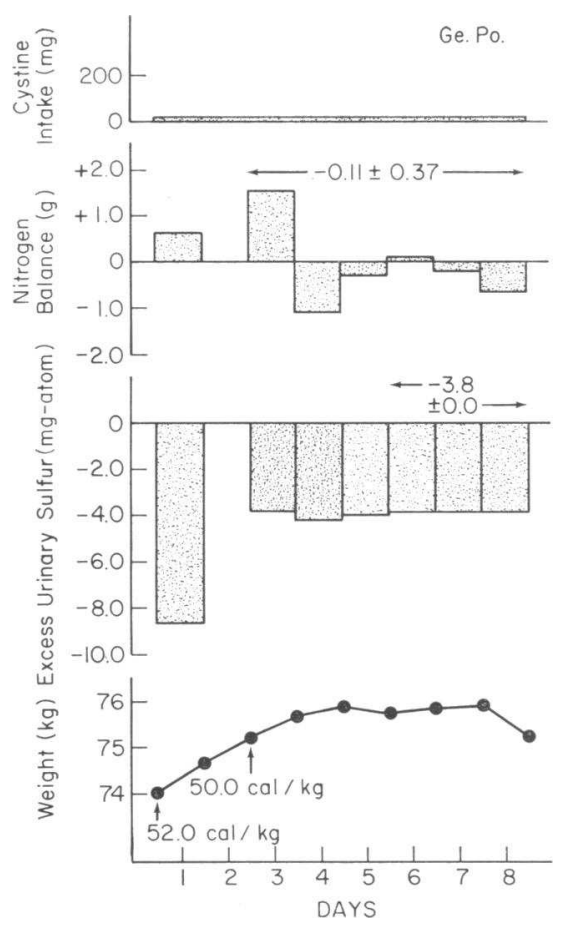

Figure 4 A study of a cystathioninuric, $B_{6}$-responsive patient (Ge. Po.) on a daily cystine intake of $6 \mathrm{mg}$. Daily intakes of methionine and nitrogen were $673 \mathrm{mg}$ and $10.86 \mathrm{~g}$, respectively, throughout. See text and Fig. 1 for further explanation.

\section{Plasma and urine amino acids}

Plasma and urine amino acid analyses were performed at least once during the latter half of each dietary balance period. In the normal controls, no changes were noted in either methionine or cystine levels, all being within normal limits on both the equilibration and the experimental diets (data not shown). The values for patients are shown in Table V. The most notable observations were the following: After the change from the equilibration diets to the experimental diets which contained less methionine, the concentrations of methionine and homocystine in plasma and the urinary excretions of homocystine decreased in cystathionine synthase-deficient, $\mathrm{B}_{\mathrm{6}}$-responsive patients Wi. Cr., Ro. Kr., and Ca. Me. but not in responder Jo. Ho. Similar changes did not occur in nonresponders Vi. Sw. and Ba. Re. Fr. Mi. was atypical among the $\mathrm{B}_{\mathrm{o}}$-nonresponsive patients and displayed changes similar to those found among the responders. All responsive patients maintained or increased their plasma cyst(e)ine concentrations, even on the lowest cystine intakes. Fr. Mi. manifested a similar tendency, although no plasma cystine was detected in one sample taken during a period of relatively low cystine intake. The cystathi- oninuric patient, Ge. Po., also increased his plasma cyst(e)ine concentration in the face of severe cystine restriction.

\section{Urinary sulfur partition studies}

The partition of total urinary sulfur between sulfate and nonsulfate sulfur should provide an index of the extent to which organic sulfur ingested as either methionine or cystine has been metabolized to the common end product sulfate. Accordingly, urinary sulfur partition studies were performed on five normal volunteers, three cystathionine synthase-deficient, pyridoxine responders, and two cystathionine synthase-deficient, pyridoxine nonresponders who did not have residual cystathionine synthase activities in their fibroblast extracts (18). Each subject received a constant natural diet calculated to provide half the dietary sulfur as methionine and half as cystine. Urinary inorganic sulfate, ethereal sulfate, and total sulfur were measured daily. Nonsulfate sulfur was then calculated as total sulfur minus total sulfate. In most cases values were obtained with the subjects receiving only normal dietary intakes of $\mathrm{B}_{\boldsymbol{s}}$ and also on high doses of pyridoxine (500 mg orally daily) (Table VI).

In their basal states (i.e., while receiving no supplemental pyridoxine) normal control subjects excreted $8.4-10.6 \%$ of their total urinary sulfur as nonsulfate sulfur. The pyridoxine-responsive patients excreted $15.3-25.9 \%$ as nonsulfate sulfur, values that in each case were significantly higher than the highest value found for a control subject $(P<0.01$ for Jo. Ho. and Ja. Is.; $P<0.05$ for Th. Kr.). The percent nonsulfate sulfur excretions of the non-Bo-responsive patients (27.5 and $31.7 \%$ ) were elevated above the control values but, surprisingly, were not significantly higher than the corresponding values found for two of the responders (Jo. Ho. and Ja. Is.). Among the responders, only Th. Kr. excreted significantly less nonsulfate sulfur than did the nonresponsive patients, Ol. Ma. and $\mathrm{Ba}$. Re.

Pyridoxine administration did not cause a statistically significant change in the percent nonsulfate sulfur excretion of any normal control. On the other hand, each of the three responsive patients showed a significant decrease in nonsulfate sulfur excretion during pyridoxine treatment $(P<0.01)$. Under these conditions, the percent nonsulfate sulfur excreted by responders Jo. Ho. and $\mathrm{Th}$. Kr. fell to values not significantly higher than the highest control value. The nonsulfate sulfur excretion of responder Ja. Is. remained marginally elevated $(0.05<P<0.10)$. For the nonresponders, pyridoxine therapy did not bring about a significant decrease in nonsulfate sulfur excretion. As a result, while the patients were on pyridoxine, the percent nonsulfate sulfur excretion of each nonresponsive patient was significantly higher than the corresponding value for each responder. 
TABLE V

Plasma and Urinary Amino Acids during Equilibration and Experimental Diets

\begin{tabular}{|c|c|c|c|c|c|c|c|c|}
\hline \multirow[b]{2}{*}{ Subject } & \multirow[b]{2}{*}{ Diet* } & \multicolumn{2}{|c|}{ Dietary intake } & \multicolumn{3}{|c|}{ Plasma amino acids $\ddagger$} & \multicolumn{2}{|c|}{ Urinary amino acids $\ddagger$} \\
\hline & & Met & Cys & Met & $\frac{1}{2}$ Cystine & Homocystine & Met & Homocystine \\
\hline \multirow{2}{*}{\multicolumn{2}{|c|}{ Cystathionine synthase deficient }} & \multicolumn{2}{|c|}{$m g$} & \multirow{2}{*}{\multicolumn{3}{|c|}{$\mu m / m l$}} & \multicolumn{2}{|r|}{$\mu m / d a y$} \\
\hline & & & & & & & & \\
\hline \multirow[t]{4}{*}{ Vi. Sw. } & Equilibration & 1,451 & 924 & - & - & $-\S$ & 354 & 368 \\
\hline & Experimental & 655 & 155 & - & - & - & 299 & 520 \\
\hline & Experimental & 655 & 305 & - & - & - & 340 & 932 \\
\hline & Experimental\| & 655 & 505 & - & - & - & 355 & 1,118 \\
\hline \multirow[t]{7}{*}{ Ba. Re. } & Equilibration & 1,613 & 1,021 & 0.462 & ND & 0.120 & 194 & 429 \\
\hline & Experimental & 667 & 509 & 0.412 & $<0.015$ & 0.118 & 155 & 348 \\
\hline & Experimental & 667 & 309 & 0.616 & ND & 0.122 & 216 & 432 \\
\hline & Experimental & 667 & 109 & - & - & - & 227 & 421 \\
\hline & Equilibration & 1,559 & 990 & 0.888 & 0.034 & 0.094 & 507 & 496 \\
\hline & Experimental & 663 & 8 & - & - & - & - & - \\
\hline & Experimental & 663 & 1,008 & 0.748 & ND & 0.069 & 88 & 147 \\
\hline \multirow[t]{4}{*}{ Fr. Mi. } & Equilibration & 1,473 & 1,124 & 0.140 & ND & 0.148 & 204 & 297 \\
\hline & Experimental & 822 & 155 & 0.064 & 0.106 & 0.010 & 126 & 25 \\
\hline & Experimental & 822 & 80 & 0.070 & ND & 0.014 & 57 & 25 \\
\hline & Experimental & 822 & 5 & 0.070 & 0.098 & 0.012 & 94 & 50 \\
\hline \multirow[t]{3}{*}{ Wi. Cr. } & Equilibration & 1,511 & 912 & 0.400 & 0.034 & 0.062 & 185 & 220 \\
\hline & Experimental & 682 & 107 & 0.076 & 0.112 & 0.008 & 65 & 25 \\
\hline & Experimental & 682 & 7 & 0.070 & 0.066 & 0.007 & 108 & 41 \\
\hline \multirow[t]{4}{*}{ Jo. Ho. } & Equilibration & 1,469 & 1,005 & 0.098 & 0.028 & 0.056 & 67 & 333 \\
\hline & Experimental & 663 & 312 & 0.104 & 0.070 & 0.024 & 83 & 165 \\
\hline & Experimental & 663 & 112 & 0.146 & 0.090 & 0.046 & 49 & 254 \\
\hline & Experimental & 663 & 12 & 0.112 & 0.056 & 0.036 & 54 & 248 \\
\hline \multirow[t]{2}{*}{ Ro. Kr. } & Equilibration & 1,444 & 995 & 0.064 & 0.112 & 0.010 & 91 & 106 \\
\hline & Experimental & 659 & 3 & 0.050 & 0.126 & $\mathrm{ND}$ & 49 & 14 \\
\hline \multirow[t]{2}{*}{ Ca. Me. } & Equilibration & 1,505 & 984 & 0.608 & ND & 0.070 & 303 & 443 \\
\hline & Experimental & 644 & 4 & 0.090 & 0.042 & 0.028 & 91 & 156 \\
\hline \multicolumn{9}{|c|}{ Cystathioninuric (presumptive $\gamma$-cystathionase deficient) } \\
\hline \multirow{2}{*}{ Ge. Po. } & Equilibration & 1,451 & 965 & 0.028 & ND & $\begin{array}{l}\text { Cystathionine } \\
\text { trace }\end{array}$ & 104 & $\begin{array}{c}\text { Cystathionıne } \\
585\end{array}$ \\
\hline & Experimental & 677 & 6 & 0.028 & 0.118 & trace & 83 & 370 \\
\hline
\end{tabular}

* The equilibration diets were composed of natural foodstuffs isonitrogenous with the experimental diets which were semisynthetic as described in Methods. The results are listed in the sequence that the studies were actually carried out.

$\ddagger$ Sample from near the end of specified dietary regimen. ND, not detected; dash (-), sample not available.

$\S$ Patient refused venipuncture.

\| This experimental period lasted 2 days only (see Table IV).

\section{DISCUSSION}

The chief aim of the present work was to evaluate as quantitatively as possible the capacities of various patients with defects in the transsulfuration pathway to biosynthesize cysteine from methionine. To this end, we measured nitrogen balances of patients and controls maintained on semisynthetic diets containing low-adequate amounts of methionine but virtually free of cyst(e)ine. The amount of supplemental cystine re- quired to achieve nitrogen equilibrium was then determined. The experiments were designed to eliminate virtually all cystine from the basal experimental diet, a consideration that dictated the use of a semisynthetic diet in which most of the amino acid intake was provided in the form of the pure compounds. The diet chosen was modelled after that often used in studies of essential amino acid requirements $(35,38-40)$ and contained the essential amino acids plus arginine, histi- 
TABLE VI

Total Urinary Sulfur and Percent Urinary Organic Sulfur on Sulfur Partition Diet: Effect of Pyridoxine*

\begin{tabular}{|c|c|c|c|c|}
\hline \multirow[b]{3}{*}{ Subject } & \multicolumn{2}{|c|}{ Total urinary sulfur } & \multicolumn{2}{|c|}{ Organic sulfur } \\
\hline & \multicolumn{2}{|c|}{ Pyridoxine supplement } & \multicolumn{2}{|c|}{ Pyridoxine supplement } \\
\hline & None & $500 \mathrm{mg}$ & None & $500 \mathrm{mg}$ \\
\hline & \multicolumn{2}{|c|}{$\mu g-\operatorname{atom} / \mathrm{kg}( \pm S E)$} & \multicolumn{2}{|c|}{$\operatorname{Percent}( \pm S E)$} \\
\hline \multicolumn{5}{|c|}{ Normal volunteers } \\
\hline Ba. Ha. & $299 \pm 10$ & - & $8.4 \pm 1.2$ & - \\
\hline Ja. Ho. $\ddagger$ & $356 \pm 35$ & $354 \pm 34$ & $10.3 \pm 1.5$ & $8.1 \pm 0.9$ \\
\hline Cr. Ki.f & $328 \pm 35$ & $341 \pm 38$ & $10.6 \pm 1.7$ & $8.4 \pm 1.4$ \\
\hline Ka. Ro. & $334 \pm 15$ & - & $9.0 \pm 1.4$ & - \\
\hline An. To. & $294 \pm 40$ & $275 \pm 19$ & $9.5 \pm 1.0$ & $12.2 \pm 1.3$ \\
\hline \multicolumn{5}{|c|}{ Cystathionine synthase-deficient $\mathrm{B}_{6}$-responders $\S$} \\
\hline Jo. Ho. & $265 \pm 12$ & $276 \pm 11$ & $25.9 \pm 1.7$ & $11.9 \pm 0.9$ \\
\hline Ja. Is. & $313 \pm 4$ & $293 \pm 24$ & $25.5 \pm 1.8$ & $16.0 \pm 1.2$ \\
\hline Th. Kr. & $304 \pm 32$ & $294 \pm 35$ & $15.3 \pm 1.3$ & $8.4 \pm 0.9$ \\
\hline \multicolumn{5}{|c|}{ Cystathionine synthase-deficient $\mathrm{B}_{6}$-nonresponders $\|$} \\
\hline Ol. Ma. & $304 \pm 24$ & $266 \pm 26$ & $31.7 \pm 2.4$ & $31.2 \pm 0.9$ \\
\hline Ba. Re. $\Uparrow$ & $283 \pm 12$ & $280 \pm 5$ & $27.5 \pm 1.8$ & $26.3 \pm 2.5$ \\
\hline
\end{tabular}

* Each subject was given a constant diet estimated to contain methionine and cystine so that each contributed $140 \mu \mathrm{g}$-atom sulfur $/ \mathrm{kg}$ body wt.

$\ddagger 20$ yr-old male.

$\S$ Residual cystathionine synthase activity was detected in fibroblast extracts from each of these patients (18).

|| No residual cystathionine synthase activity was detected in fibroblast extracts of either of these patients (18).

I Corrected for sulfur content of medications taken by this subject. The maximum uncertainty in organic sulfur due to these corrections is $1 \%$. dine, and tyrosine in the approximate amounts found in $20 \mathrm{~g}$ whole egg protein. Supplemental glycine was added to keep the experimental diets isonitrogenous with the equilibration diets $(35,38-40)$. This level and pattern of amino acid intake satisfied an additional desideratum to keep the methionine intake reasonably low to avoid insofar as possible the accumulation of what might be considered "toxic" concentrations of methionine metabolites in the patients with transsulfuration defects. As has been pointed out (41) this diet satisfies the minimum essential amino acid requirements proposed by Rose and Wixom (42) and others $(43,44)$. However, recent results suggest that this regimen may be marginally inadequate for maintenance of true nitrogen balance $(41,45,46)$. Although, in practice, our normal subjects on the basal semisynthetic diet containing virtually no cystine remained within the zone of nitrogen equilibrium (Table III), these relatively short-term studies do not prove the complete, long-term nutritional adequacy of the diets employed. Longer studies, or adoption of "corrected" rather than "apparent" nitrogen balances (47) might have indicated that the basal diet used was inadequate.

An additional criterion for comparison of normals and patients is afforded by the measurements of excess urinary sulfur performed in the course of our studies. Again, it is noted that these measurements do not test the long-term adequacy of any particular dietary regimen. For this purpose, true balances taking into account fecal and other losses would be needed.

In Table VII the results on our present patients, as well as the patient studied by Brenton and coworkers

TABLE VII

Patients with Transsulfuration Defects:

$B_{6}$-Responsiveness, Presence of Detected Residual Enzyme Activity, and Presence of Excessive Loss of Nitrogen or Sulfur on Lowest Cystine Intake Studied*

\begin{tabular}{|c|c|c|c|c|c|}
\hline \multirow[b]{2}{*}{ Patient } & \multirow[b]{2}{*}{ Defective enzyme } & \multirow[b]{2}{*}{ B $_{6}$-responsive } & \multirow{2}{*}{$\begin{array}{l}\text { Residual enzyme } \\
\text { detected }\end{array}$} & \multicolumn{2}{|c|}{ Excessive loss of : } \\
\hline & & & & Nitrogen & Sulfur \\
\hline Stuart M. & Cystathionine synthase & No & Unknown & Yes & Unknown \\
\hline Vi. Sw. & Cystathionine synthase & No & No & Yes & Yes \\
\hline Ba. Re. & Cystathionine synthase & No & No & $?$ & Yes \\
\hline Fr. Mi. & Cystathionine synthase & No & Yes & No & No \\
\hline Wi. Cr. & Cystathionine synthase & Yes & Yes & No & No \\
\hline Jo. Ho. & Cystathionine synthase & Yes & Yes & No & No \\
\hline Ro. Kr. & Cystathionine synthase & Yes & Yes & ? & No \\
\hline Ca. Me. & Cystathionine synthase & Yes & Yes & No & No \\
\hline Ge. Po. & $\gamma$-Cystathionase & Yes & Unknown & No & Slight \\
\hline
\end{tabular}

* Data on $\mathrm{B}_{6}$-responsiveness and enzyme assays are recorded or referred to in Table I. The nitrogen and sulfur losses are those for the lowest cystine intake tested for each patient (Table IV).

$\ddagger$ Studied by Brenton et al. (9). This patient was subsequently shown to be unresponsive to pyridoxine (D. C. Cusworth, personal communication).

1044 J. R. Poole, S. H. Mudd, E. B. Conerly, and W. A. Edwards 
(9), are summarized. It has previously been shown that there is a strong correlation between the presence or absence of detected residual cystathionine synthase activity in cystathionine synthase-deficient patients and their clinical responsiveness or nonresponsiveness to $\mathrm{B}_{0}$ administration. Residual cystathionine synthase activities were not detected in fibroblasts of 11 of $13 \mathrm{~B}$-nonresponsive patients (18 and our unpublished results), nor in liver of two of two nonresponders (48). Among the patients in Table VII, Vi. Sw. and Ba. Re. fall into the category of $\mathrm{B}_{\mathrm{o}}$-nonresponsive patients without detected residual cystathionine synthase activity. Stuart M. is $\mathrm{B}_{\mathrm{r}}$-nonresponsive. Although he has not yet been categorized with respect to residual enzyme activity, the results described above make it statistically likely that he lacks such activity. Each of these three patients evidently lost excessive nitrogen and/or sulfur when placed on low cystine intakes. These losses were reversed by increasing the cystine intakes (except, questionably, for the nitrogen loss of Ba. Re.).

In contrast to the results with most $\mathrm{B}_{6}$-nonresponsive patients, sensitive assays did detect measurable residual cystathionine synthase activities $(0.1-10 \%$ of the mean control value) in liver and/or fibroblasts extrasts of each of the 25 responsive patients we studied $(18,19$, 49 ), as well as seven of seven B $B_{-}$-responders studied by others (48, 50, 51). Wi. Cr., Jo. Ho., Ro. Kr., and $\mathrm{Ca}$. Me. are in this category of $\mathrm{B}_{8}$-responsive cystathionine synthase-deficient patients with detected residual enzyme activity. None of these patients were significantly below the zone of nitrogen equilibrium or lost more sulfur than did our control subjects on diets virtually free of cystine.

Fr. Mi. falls into the relatively infrequently encountered class of cystathionine synthase-deficient $\mathrm{B}_{\boldsymbol{\theta}}$-nonresponders with detected residual enzyme activity (18). Such patients illustrate that the presence of residual cystathionine synthase activity is a necessary but not sufficient condition for $\mathrm{B}_{\mathrm{e}}$-responsiveness. Fr. Mi. had no excessive loss of either nitrogen or sulfur, even when his cystine intake was lowered to $5 \mathrm{mg}$ daily.

Thus, among the eight cystathionine synthase-deficient patients studied to date, the five with residual enzyme activities could not be shown to require more cystine than do normal subjects. There is no indication that for these patients cystine is an essential amino acid. In contrast, for the three patients without detected residual enzyme activities, the evidence clearly suggests a requirement for exogenous cystine in two, and the clinical signs and sulfur losses of the third patient are suggestive of such a requirement. It appears that the generalization that cystine is an essential amino acid for cystathionine synthase-deficient patients (2, $10-17)$ is not universally correct and that in all likelihond the presence of a residual few percent of the nor- mal control cystathionine synthase activity is sufficient to obviate this requirement.

How much cyst(e)ine must be generated endogenously to avoid a requirement for exogenous cyst(e)ine in a cystathionine synthase-deficient patient without residual activity of this enzyme? The nitrogen balance of the Bo-nonresponder studied by Brenton et al. on a daily cystine intake of $85 \mathrm{mg}$ was $-1.12 \pm 0.23 \mathrm{~g} /$ day (estimated from Fig. 13 of reference 9). Nitrogen balance was restored with a cystine intake of $1,085 \mathrm{mg}$. Intermediate intakes of cystine were not studied. The nitrogen balance of our patient Vi. Sw. was $-0.96 \pm 0.16$ $\mathrm{g} /$ day on a daily cystine intake of $155 \mathrm{mg}$. Nitrogen equilibrium was restored and excessive urinary nitrogen loss was prevented by an intake of $505 \mathrm{mg}$. The urinary sulfur loss of Vi. Sw. remained slightly excessive on $305 \mathrm{mg}$ cystine. These studies suggest a cystine requirement of between 305 and $505 \mathrm{mg}$ for Vi. Sw. The results with patient $\mathrm{Ba}$. Re. are more difficult to interpret because nitrogen equilibrium was not restored with certainty even on a cystine intake as high as $1,008 \mathrm{mg}$. Judging by the clinical responses of $\mathrm{Ba}$. Re. to various cystine intakes and by her urinary sulfur losses, it may be tentatively estimated that 309-509 mg of cystine was adequate for this patient. Also pertinent are studies of $\mathrm{Bu}$. Ha., another cystathionine synthase-deficient $\mathrm{B}_{6}-$ nonresponsive patient without significant detected cystathionine synthase activity in fibroblast extracts (18). The results obtained with this 8-yr-old boy were not included in Table IV because he could not be persuaded to accept the semisynthetic experimental diet. Accordingly, a normal food diet was devised, calculated to provide $577 \mathrm{mg}$ of methionine, $307 \mathrm{mg}$ of cystine, and 4.13 $\mathrm{g}$ of nitrogen. Supplemental glycine was added to bring the total nitrogen intake to $10.7 \mathrm{~g}$. On this diet, the nitrogen balance was $+1.98 \pm 0.46 \mathrm{~g}$ and excess urinary sulfur was $-1.4 \mathrm{mg}$-atom/day. All of these observations together suggest that $310-510 \mathrm{mg}$ cystine is adequate for patients with virtually no residual cystathionine synthase activity detected by present methods. Because of the small number of patients studied, it should be clear that at best these estimates are approximations of the amount of cystine needed to prevent excessive nitrogen or sulfur losses under our conditions.

If cystathionine synthase-deficient patients without detected residual enzyme required $310-510 \mathrm{mg}$ cystine under these conditions, it follows that the patients with residual cystathionine synthase activities who remained in equilibrium on diets containing adequate methionine, but at most $12 \mathrm{mg}$ cystine, were forming endogenously at least $300-500 \mathrm{mg}$ (i.e., $2.5-4.0 \mathrm{mmol}$ ) cysteine. The sulfur for this cysteine must ultimately have derived from methionine, since there was no other major dietary sulfur source. The values of $2.5-4.0 \mathrm{mmol}$ (which are minimum estimates since our experiments would not 
detect the formation of more cysteine that would be required to sustain equilibrium) are equivalent to 20$50 \%$ of the normal dietary intake of methionine of 8-12 $\mathrm{mmol}$. The hepatic cystathionine synthase activities of our $\mathrm{B}_{\mathrm{e}}$-responsive patients in their basal states (i.e., on $\mathrm{B}_{\boldsymbol{8}}$ intakes provided by normal diets only) were $1-2 \%$ of the mean control value $(19,49)$. Thus, it appears that a residual activity of $1-2 \%$ of this enzyme endows the patient with the capacity to convert at least $20-50 \%$ of the normal methionine intake to cysteine. Our working hypothesis as to the mechanism of action of $\mathrm{B}_{8}$ in responsive patients is that vitamin administration brings about an increase of 2-4-fold in the basal enzyme activity of such patients $(18,19)$. The present demonstration that the basal residual enzyme activity is capable of metabolizing $20-50 \%$ of the normal methionine intake is clearly compatible with and supports this working hypothesis. To be able to metabolize the normal methionine intake without undue homocysteine accumulation it may be necessary to possess no more than a relatively small portion of the mean control cystathionine synthase activity.

Cystathionine synthase catalyzes also the sulfhydration of serine to form cysteine $(52,53)$. If cystathionine synthase-deficient patients retain a disproportionate share of the normal serine sulfhydrase activity, it is possible that reaction accounts for the residual capacity to form cysteine demonstrated during the present work. This possibility, which in our opinion is not very likely, could be evaluated by assays of serine sulfhydrase in cells of patients who do not require cystine and by determination of cystathionine concentrations before and during response to $B_{6}$.

The nutritional approach used in the present work to determine the residual metabolic capacities of patients with cystathionine synthase deficiency might usefully be extended to other enzymopathies. One example, of such an extension is provided by the study reported here of

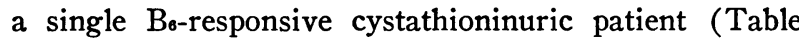
IV). ${ }^{3}$ Enzyme assays and nutritional studies of $\gamma$-cystathionase-deficient patients not responsive to $B_{B}(5,54)$ would be of interest, as would a correlation of residual enzyme activities of phenylalanine hydroxylase and the tyrosine requirements of patients with phenylketonuria and its variants.

Note added in proof. Two full-length reports especially pertinent to this paper have recently appeared. The results

\footnotetext{
${ }^{3}$ The results of a methionine loading study with Ge. Po. are consistent with his possessing some residual $\gamma$-cystathionase activity. In the $24 \mathrm{~h}$ following an oral dose of $\mathrm{L}-$ methionine, $36.9 \mathrm{mmol}$, this patient excreted in his urine an increment of $17.1 \mathrm{mmol}$ of total sulfur. The increment in daily excretions of cystathionine and total sulfate were, respectively, 4.0 and $11.3 \mathrm{mmol}$. Thus, Ge. Po. had converted a major portion of the methionine sulfur to sulfate within 24 h.
}

of Gaull, Sturman, and Schaffner (55) generally support the hypothesis that $B_{6}$ treatment brings about increases in residual hepatic cystathionine synthase activities of responsive patients. The mean basal activity in four responsive patients under the conditions employed was $6 \%$ of the mean control value; the mean activity during response, $18 \%$. Porter, Grishaver, and Jones (56) found that extracts of fibroblasts from a $\mathrm{B}_{\mathrm{o}}$-responsive patient retained $8 \%$ residual capacity to form cystathionine from homocysteine and serine, whereas no residual capacity to form cysteine from $\mathrm{Na}_{2} \mathrm{~S}$ and serine was detected.

\section{ACKNOWLEDGMENTS}

We wish to thank Miss Paula Parisius and Mr. Byron Baer for performing the micro-Kjeldahl analyses, Drs. Josette Bianchine, Richard Erbe, Stephen Goodman, Neil Holtzman, John Littlefield, Victor McKusick, Grant Morrow, III, Andrew Sass-Kortsak, C. Ronald Scott, and David C. Siggers for allowing us to study their patients, Miss Ernestina Bou and Miss Mary Casey for aid with the diets, Mrs. Libby Ely and Mrs. Barbara Latrobe for social work assistance, and Mr. Larry Kleinman for help in the preparation of the amino acid mixtures. Mrs. Karen Pettigrew was of invaluable assistance in carrying out statistical analyses of the data. Dr. B. William Uhlendorf kindly provided fibroblasts for enzyme analyses.

\section{REFERENCES}

1. Mudd, S. H., J. D. Finkelstein, F. Irreverre, and L. Laster. 1964. Homocystinuria: an enzymatic defect. Science (Wash. D. C.). 143: 1443-1445.

2. Mudd, S. H. 1971. Homocystinuria: the known causes. In Inherited Disorders of Sulphur Metabolism. N. A. J. Carson and D. N. Raine, editors. Churchill Livingstone, Edinburgh. 204-221.

3. Frimpter, G. W. 1965. Cystathioninuria: nature of the defect. Science (Wash. D. C.). 149: 1095-1096.

4. Finkelstein, J. D., S. H. Mudd, F. Irreverre, and L. Laster. 1966. Deficiencies of cystathionase and homoserine dehydratase activities in cystathioninuria. Proc. Natl. Acad. Sci. U. S. A. 55: 865-872.

5. Tada, K., T. Yoshida, Y. Yokoyama, T. Sato, H. Nakagawa, and T. Arakawa. 1968. Cystathioninuria not associated with vitamin $B_{\theta}$ dependency: a probably new type of cystathioninuria. Tohoku J. Exp. Med. 95: 235242.

6. Carson, N. A. J., D. C. Cusworth, C. E. Dent, C. M. B. Field, D. W. Neill, and R. G. Westall. 1963. Homocystinuria: a new inborn error of metabolism associated with mental deficiency. Arch. Dis. Child. 38: 425436.

7. Rose, W. C., J. E. Johnson, and W. J. Haines. 1950. The amino acid requirements of man. I. The role of valine and methionine. J. Biol. Chem. 182: 541-556.

8. Rose, W. C., M. J. Coon, H. B. Lockhart, and G. F. Lambert. 1955. The amino acid requirements of man. XI. The threonine and methionine requirements. J. Biol. Chem. 215: 101-110.

9. Brenton, D. P., D. C. Cusworth, C. E. Dent, and E. E. Jones. 1966. Homocystinuria. Clinical and dietary studies. Q. J. Med. 35: 325-346.

10. Gaull, G. E. 1967. The pathogenesis of homocystinuria. Implications for treatment. Am. J. Dis. Child. 113: 103108.

11. Cusworth, D. C., and C. E. Dent. 1969. Homocystinuria. Br. Med. Bull. 25 : 42-47. 
12. Milne, M. D. 1970. Some abnormalities of amino acid metabolism. In Biochemical Disorders in Human Disease. R. H. S. Thompson and I. D. P. Wootton, editors. J. \& A. Churchill Ltd., London. 553-607.

13. Sotos, J. F., and D. E. Boggs. 1970. Disorders of metabolism. In Genetic Disorders of Man. R. M. Goodman, editor. Little, Brown and Company, Boston. 829907.

14. Perry, T. L. 1971. Treatment of homocystinuria with a low-methionine diet and supplemental L-cystine. In Inherited Disorders of Sulphur Metabolism. N. A. J. Carson and D. N. Raine, editors. Churchill Livingstone, Edinburgh. 245-253.

15. Gerritsen, T. 1971. General discussion on the treatment of homocystinuria. In Inherited Disorders of Sulphur Metabolism. N. A. J. Carson and D. N. Raine, editors. Churchill Livingstone, Edinburgh. 303-312.

16. Gerritsen, T., and H. A. Waisman. 1972. Homocystinuria. Cystathionine synthase deficiency. In The Metabolic Basis of Inherited Disease. J. B. Stanbury, J. B. Wyngaarden, and D. S. Fredrickson, editors. McGrawHill Book Co., New York. 3rd edition. 404-412.

17. Perry, T. L. 1974. Homocystinuria. In Heritable Disorders of Amino Acid Metabolism. W. L. Nyhan, editor. McGraw-Hill Book Co., New York. 395-428.

18. Uhlendorf, B. W., E. B. Conerly, and S. H. Mudd. 1973. Homocystinuria: studies in tissue culture. Pediatr. Res. $7: 645-658$

19. Mudd, S. H., W. A. Edwards, P. M. Loeb, M. S. Brown, and L. Laster. 1970. Homocystinuria due to cystathionine synthase deficiency: the effect of pyridoxine. J. Clin. Invest. 49: 1762-1773.

20. Sardharwalla, I. B., S. H. Jackson, H. D. Hawke, and A. Sass-Kortsak. 1968. Homocystinuria: a study with low-methionine diet in three patients. Canad. Med. Assoc. J. 99 : 731-740.

21. Scott, C. R., S. W. Dassell, S. H. Clark, C. ChiangTeng, and K. R. Swedberg. 1970. Cystathioninemia: a benign genetic condition. J. Pediatr. 76: 571-577.

22. Barber, G. W., and G. L. Spaeth. 1967. Pyridoxine therapy in homocystinuria. Lancet. 1: 337.

23. Orr, M. L., and B. K. Watt. 1957. Amino acid content of foods. U. S. Dept. Agric. Home Econ. Res. Rep. No. 4.82 pp.

24. Nakagawa, I., T. Takahashi, and T. Suzuki. 1961. Amino acid requirements of children: minimal needs of lysine and methionine based on nitrogen balance method. J. Nutr. 74: 401-407.

25. Ma, T. S., and G. Zuazaga. 1942. Micro-Kjeldahl determination of nitrogen. A new indicator and an improved rapid method. Ind. Eng. Chem. Anal. Ed. 14: 280-282.

26. Chasson, A. L., H. J. Grady, and M. A. Stanley. 1961. Determination of creatinine by means of automatic chemical analysis. Am. J. Clin. Pathol. 35: 83-88.

27. Spackman, D. H., W. H. Stein, and S. Moore. 1958. Automatic recording apparatus for use in the chromatography of amino acids. Anal. Chem. 30: 1190-1206.

28. Woodring, M. J., D. H. Fisher, and C. A. Storvick. 1964. A microprocedure for the determination of 4pyridoxic acid in urine. Clin. Chem. 10: 479-489.

29. Harper, T. A. 1965. A modified 'aseptic addition' assay procedure for the measurement of serum 'folic-acid' activity. Nature (Lond.). 207: 947-949.

30. Hawk, P. B., B. L. Oser, and W. H. Summerson. 1954. Practical Physiological Chemistry. Blakiston Division of the McGraw-Hill Book Co., Inc., New York. 13th edition. 949-950.

31. Grubbs, F. E. 1969. Procedures for detecting outlying observations in samples. Technometrics. 11: 1-21.

32. Carey, M. C., J. J. Fennelly, and O. Fitzgerald. 1968. Homocystinuria. II. Subnormal serum folate levels, increased folate clearance and effects of folic acid therapy. Am. J. Med. 45: 26-31.

33. Morrow, G., III, and L. A. Barness. 1972. Combined vitamin responsiveness in homocystinuria. J. Pediatr. 81 : 946-954.

34. Reddy, S. K., M. S. Reynolds, and J. M. Price. 1958. The determination of 4-pyridoxic acid in human urine. J. Biol. Chem. 233: 691-696.

35. Leverton, R. M., M. R. Gram, M. Chaloupka, E. Brodovsky, and A. Mitchell. 1956. The quantitative amino acid requirements of young women. I. Threonine. $J$. Nutr. 58: 59-81.

36. Swendseid, M. E., I. Williams, and M. S. Dunn. 1956. Amino acid requirements of young women based on nitrogen balance data. I. The sulfur-containing amino acids. J. Nutr. 58 : 495-505.

37. Leverton, R. M., N. Johnson, J. Ellison, D. Geschwender, and F. Schmidt. 1956. The quantitative amino acid requirements of young women. IV. Phenylalanine, with and without tyrosine. J. Nutr. 58: 341-353.

38. Swendseid, M. E., and M. S. Dunn. 1956. Amino acid requirements of young women based on nitrogen balance data. II. Studies on isoleucine and on minimum amounts of the eight essential amino acids fed simultaneously. J. Nutr. 58: 507-517.

39. Jones, E. M., C. A. Baumann, and M. S. Reynolds. 1956. Nitrogen balances of women maintained on various levels of lysine. J. Nutr. 60: 549-562.

40. Reynolds, M. S., D. L. Steel, E. M. Jones, and C. A. Baumann. 1958. Nitrogen balances of women maintained on various levels of methionine and cystine. J. Nutr. 64: 99-111.

41. Weller, L. A., D. H. Calloway, and S. Margen. 1971. Nitrogen balance of men fed amino acid mixtures based on Rose's requirements, egg white protein, and serum free amino acid patterns. J. Nutr. 101: 1499-1507.

42. Rose, W. C., and R. L. Wixom. 1955. The amino acid requirements of man. XVI. The role of the nitrogen intake. J. Biol. Chem. 217: 997-1004.

43. Hegsted, D. M. 1963. Variation in requirements of nutrients-amino acids. Fed. Proc. 22: 1424-1430.

44. Reynolds, M. S. 1958. The amino acid requirements of adults. A review. Am. J. Clin. Nutr. 6: 439-442.

45. Calloway, D. H., and S. Margen. 1971. Variation in endogenous nitrogen excretion and dietary nitrogen utilization as determinants of human protein requirement. J. Nutr. 101 : 205-216.

46. Young, V. R., Y. S. M. Taylor, W. M. Rand, and N. S. Scrimshaw. 1973. Protein requirements of man. Efficiency of egg protein utilization at maintenance and submaintenance levels in young men. J. Nutr. 103: 1164-1174.

47. Calloway, D. H., A. C. F. Odell, and S. Margen. 1971. Sweat and miscellaneous nitrogen losses in human balance studies. J. Nutr. $101:$ :775-786.

48. Gaull, G. E., F. Schaffner, and J. A. Sturman. 1973. Cystathionine synthase deficiency: enzymatic and ultrastructural studies of liver from heterozygotes and from homozygotes treated with pyridoxine. Pediatr. Res. 7: 347. (Abstr.) 
49. Mudd, S. H., L. Laster, J. D. Finkelstein, and F. Irreverre. 1967. Studies on homocystinuria. In Amines and Schizophrenia. H. E. Himwich, S. S. Kety, and J. R. Smythies, editors. Pergamon Press, Inc., Elmsford, N. Y. 247-256.

50. Yoshida, T., K. Tada, T. Yokoyama, and T. Arakawa. 1968. Homocystinuria of vitamin $B_{\sigma}$-dependent type. Tohoku J. Exp. Med. 96: 235-242.

51. Seashore, M. R., J. L. Durant, and L. E. Rosenberg. 1972. Studies of the mechanism of pyridoxine-responsive homocystinuria. Pediatr. Res. 6: 187-196.

52. Braunstein, A. E., E. V. Goryachenkova, E. A. Tolosa, I. H. Willhardt, and L. L. Yefremova. 1971. Specificity and some other properties of liver serine sulphhydrase: evidence for its identity with cystathionine $\beta$-synthase. Biochim. Biophys. Acta. 242 : 247-260.
53. Jones, O. W., and M. A. Grishaver. 1973. A possible bifunctional role for cystathionine synthase. Pediatr. Res. 7 : 343. (Abstr.)

54. Levy, H. L., S. H. Mudd, and P. M. Madigan. 1973. Pyridoxine-unresponsive cystathioninemia. Pediatr. Res. $7: 390$. (Abstr.)

55. Gaull, G., J. A. Sturman, and F. Schaffner. 1973. Homocystinuria due to cystathionine synthase deficiency: enzymatic and ultrastructural studies. J. Pediatr. 84: 381390.

56. Porter, P. N., M. S. Grishaver, and O. W. Jones. 1974. Characterization of human cystathionine $\beta$-synthase. Evidence for the identity of human L-serine dehydratase and cystathionine $\beta$-synthase. Biochim. Biophys. Acta. 364 : 128-139. 